\title{
Which Information is Commonly Used for Patients with Stroke at Rehabilitation Settings?
}

Haejung Lee, Jumin Song

Department of Physical Therapy, Silla University, Busan, Korea

Purpose: To explore the functioning information in the current medical records for patients with stroke using the comprehensive International Classification of Functioning, Disability and Health (ICF) coreset for Stroke.

Methods: Physical therapists, who have more than 3 years of clinical experience in neurologic therapeutic area, filled out the coreset for Stroke based on their patients' medical records, and an interview was conducted for them. Each of the categories in the coreset was analyzed using frequency and percentage analysis.

Results: A total of ninety patients with stroke were evaluated. Five categories of neuromusculoskeletal and movement functions in the body function domain were rated as having problems in over $90 \%$ of the patients. Four categories of the body structure domain were found as having a problem in over $73 \%$ of patients. In the domain of activity and participation, eight categories related to function of domestic lives, areas of major life and mobility were identified as having a problem for more than $90 \%$ of those patients. In the environmental factors, a category of health professionals was documented as facilitator in $87 \%$ of patients whilst nine categories, including products and technology, physical geography, services, systems and policies, were rated as barriers by more than 10\% of patients.

Conclusion: The current medical records of patients with stroke contain functioning information. Information regarding body function, and activity and participation was mainly focused on rehabilitation services. It is suggested that environmental factors should be included to understand patients' life situation which may have impact on patients' functioning.

Keywords: ICF, Stroke, Medical recordings

\section{INTRODUCTION}

WHO has proposed a biopsychosocial approach to health, functioning, and disability as new model of human functioning and disability. The new International Classification of Functioning, Disability and Health (ICF) model was developed to reflect the interactive relationship between health conditions and contextual factors. ${ }^{1}$ The ICF model represents current world views of health and disability, and it is already being used in many countries for multiple purposes including a framework for social policy, research, education and clinical practice. ${ }^{2}$

ICF consists of four domains: body functions, body structure, activities and participation, and environmental factors. Body functions are defined as the physiological function of body systems, and

Received Nov 14, 2015 Revised Dec 16, 2015

Accepted Dec 21, 2015

Corresponding author Jumin Song

E-mail jmsong@silla.ac.kr body structures refer to the anatomical parts of the body. Abnormalities of body function and structure are referred to as impairments. Activity is the execution of a task or action by an individual which represents the individual perspective of functioning. Participation refers to the involvement of an individual in a life situation which represents the social perspective of functioning. ${ }^{3}$ Difficulties at the activity level are referred to as activity limitation. Problems an individual may experience in his or her involvement in life situations are included as participation restriction. Environmental factors consist of the physical, social and attitudinal environments in which people live and conduct their lives. These factors are external to individuals and can have a positive or negative influence, which may be indicated as a facilitator or a barrier respectively for the individual. $^{4}$ 
In the clinical practice, medical records of patients are used for communication between professionals, clinical decision makings, and creation of legal records. They can also estimate expenses for provided health services. Medical records may include examination, evaluation, diagnosis, prognosis, intervention, and outcomes relevant to individuals' health status in a standardised manner. In rehabilitation, health-status measures are used for the assessment of patients problems, intervention management and outcome evaluation. ${ }^{2}$ Stroke is the number one cause of the neurologic disability worldwide, and is characterized by both cognitive and motor impairments, which contribute to functional dependence and reduced quality of life. ${ }^{5}$ Muscle power, range of motion, fine hand function, spasticity, respiratory function, walking, grasping or carrying, selfcare are commonly recorded in current rehabilitation settings in Korea to understand stroke patients' conditions. ${ }^{6-10}$ Restrictions in working, recreation and leisure, and interpersonal relationship including family and friends are also important aspect to patients with stroke.

ICF has the worldwide standard for reporting on functioning and disability and potential value to establish treatment plans for patients, which is applied as a useful framework for measuring the disability and functions in stroke-related clinical research. Recently, a series of ICF core sets have been developed to characterize the specific problems and/or patient population. The comprehensive ICF coreset for a specific condition is a list of ICF categories that depict the typical spectrum of problems in functioning of patients with that condition including stroke. ${ }^{11}$ Each ICF core set is purpose-oriented and concise, and can be used in daily clinical practice. ${ }^{12}$

Many instruments are commonly used to measure individuals' level of function and also information of individuals disability and functioning capacity are collected in the clinical settings. Those information could be linked into ICF so that a clearer understanding of the affecting patients' functioning to help clinician's decision making for clinical practice. However, there is no data available whether functioning information is actually recorded in the current medical recordings to understand individuals' health status. Therefore, the purpose of the study was to investigate functioning information in the current medical recordings for patients with stroke and link them into ICF to understand what kind information is commonly used for patients with stroke at rehabilitation settings.

\section{METHODS}

\section{Subjects and study periods}

Data was collected from twelve rehabilitation hospitals and centers in Busan, Daegu, Daejeon, Gwangju, Ulsan, Jeju and Changwon. Fifteen therapists from 12 institutes participated to collect data. To achieve quality of data for the study, therapists who had an ICF education workshop and understood ICF were invited. Data collection was performed from June to September, 2015. Patients, diagnosed with stroke by medical doctors based on clinical and investigation features, and had undergone rehabilitation services, were also invited to the study.

\section{Study contents and design}

The study was a multicenter cross-sectional study. The coreset was applied by physical therapists. The data of core set was collected based on information gathered from patient's medical recordings including case history, patient-reported outcome, and clinical examination. When patients were asked about their problems, they wished to discuss regarding their functioning. Informed consent was obtained from the participating subjects prior to data collection.

\section{Measurement and Methods}

Fifteen physical therapists, who have minimum of 3 year clinical experience in neurologic therapeutic area, filled out the core set for stroke based on their patients' medical records and an interview. In the interview, difficulty of daily activities, eg modified Bathel index, were asked. The coreset is composed of 130 categories from four domains: body function (41 categories), body structures (5 categories), activity and participation (51 categories), and environmental factors (33 categories). The qualifier scale has five response options designed to assess categories of body function, body structure and activity \& participation domains. Scores of 0, 1, 2, 3, and 4 indicate no, mild, moderate, severe and complete impairment, or limitation/ restriction respectively. Whereas the qualifier scale of environmental factors has nine response options ranging from 4 to +4 , a score of 1 to 4 refers to a barrier to environmental factors, while a score of +1 to +4 represents a facilitator to environmental factors. A score of 0 may be regarded as no influence in a patient's life. In addition, there are response options of ' 8 ' and ' 9 ' indicating 'not specified' and 'not applicable' respectively. 


\section{Statistical Analysis}

Collected data was evaluated using the frequency and percentage of patients who had a problem for each category in body function, body structure and activity and participation. For the categories of environmental factors, the frequency of reported categories as a barrier or a facilitator was calculated. The qualifiers ' 8 (not specified)' and '9 (not applicable)' were treated as missing value based on the assumption that if a determined ICF category is not specified or not applicable to a patient, it is not known whether it is problem for the patient or not. For the component of environmental factors, response options from 1 to 4 were recorded as from -1 to -4 respectively for a barrier, while scores from +1 to +4 were recorded as from 1 to 4 for a facilitator respectively. Descriptive data analysis was performed using SPSS version 22 (SPSS Inc., Chicago, IL, USA).
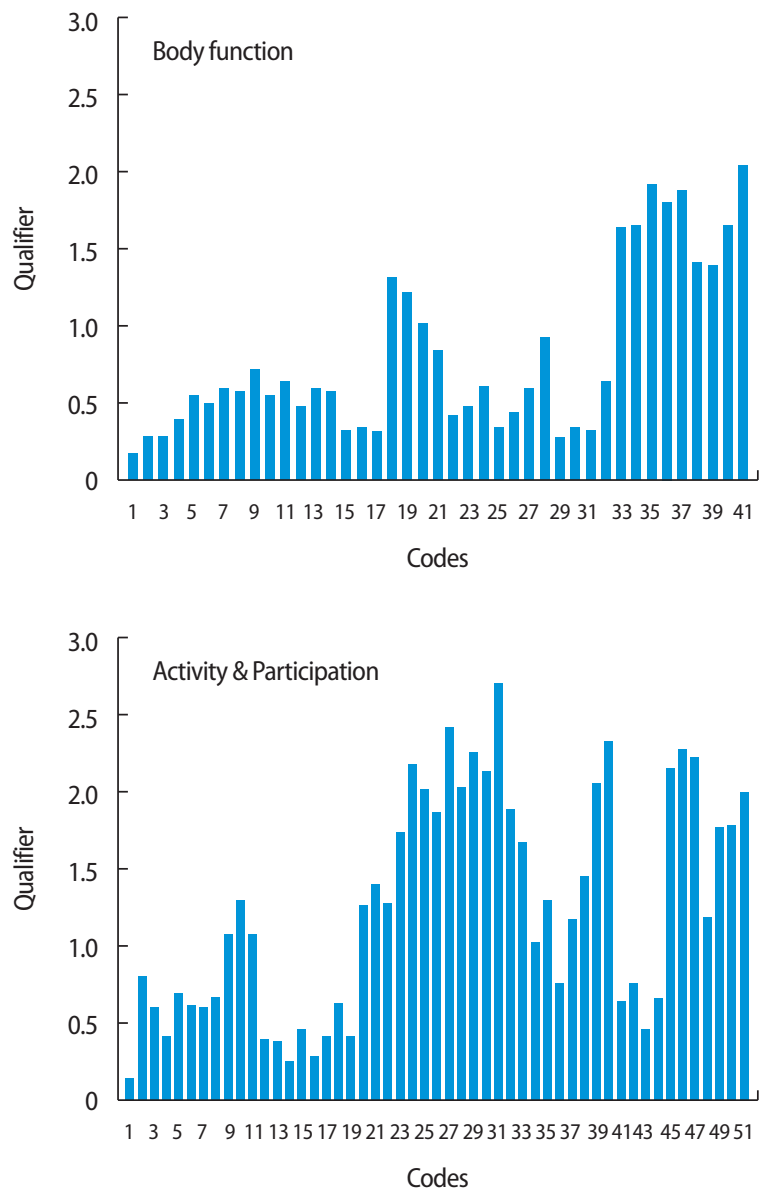

\section{RESULTS}

Ninety patients with stroke, mean age of $54.5(\mathrm{SD}= \pm 12.3)$ years, were included in the study. All participants suffered from stroke longer than 3 months and 56 of them were male. Forty-three out of 90 participants had intra-cerebral hemorrhage, 47 of whom had cerebral infarction. Forty-two of them had stroke with left symptoms. Each code was presented in Figure 1 with mean of qualifier.

Frequency of response rate in each chapter of functioning domains is presented in the Table 1. The Body function domain was the most responded by participants whereas the body structure domain had least response rate across domains. In the body function domain, functions related to voice and speech and those of the digestive, metabolic and endocrine systems were documented in most chapters with $100 \%(n=90)$ of patients. While chapters of the car-
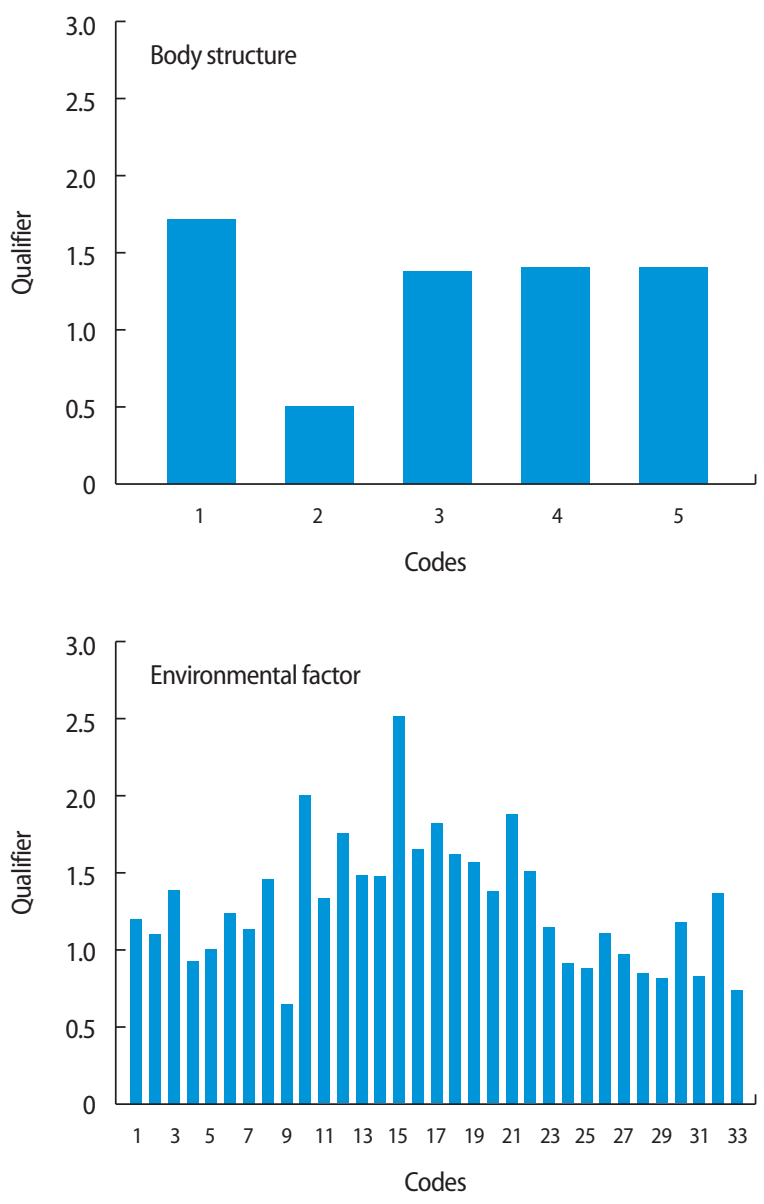

Figure 1. Distribution of each domain and each code. Code labels in each graph represent ICF codes in the core set. Each corresponding code is described in the appendix. 
Table 1. Percentage of impairment in body function and structures, limitation and restriction of activity and participation components. Each chapter refers to body function, body structure and activity \& participation

(Unit: \%)

\begin{tabular}{|c|c|c|c|c|c|c|c|}
\hline \multirow{2}{*}{ Domain } & \multirow{2}{*}{ Chapter } & \multicolumn{6}{|c|}{ Qualifier* } \\
\hline & & 0 & 1 & 2 & 3 & 4 & Missing \\
\hline \multirow[t]{7}{*}{ Body function } & b1: Mental functions & 62.6 & 29.8 & 6.1 & 1.0 & 0.3 & 0.1 \\
\hline & b2: Sensory functions and pain & 48.5 & 28.9 & 15.2 & 5.4 & 1.9 & 0.2 \\
\hline & b3: Voice and speech functions & 35.4 & 8.0 & 3.7 & 3.0 & 0.0 & 0.0 \\
\hline & b4: Functions of the cardiovascular, haematological, immunological and respiratory systems & 53.1 & 34.7 & 5.6 & 2.8 & 0.0 & 3.9 \\
\hline & b5: Functions of the digestive, metabolic and endocrine systems & 79.4 & 15.0 & 2.8 & 2.8 & 0.0 & 0.0 \\
\hline & b6: Genitourinary and reproductive functions & 65.6 & 22.2 & 4.4 & 3.3 & 0.6 & 3.9 \\
\hline & b7: Neuromusculoskeletal and movement-related functions & 7.4 & 33.5 & 41.6 & 15.7 & 1.6 & 0.2 \\
\hline \multirow[t]{3}{*}{ Body structure } & s1: Structures of the nervous system & 3.3 & 26.7 & 53.3 & 6.7 & 0.0 & 10.0 \\
\hline & s4: Structures of the cardiovascular, immunological and respiratory systems & 45.6 & 11.1 & 8.9 & 1.1 & 0.0 & 33.3 \\
\hline & s7: Structures related to movement & 18.1 & 31.5 & 33.3 & 7.8 & 1.9 & 7.4 \\
\hline Activity \& & d1: Learning and applying knowledge & 58.9 & 30.6 & 8.1 & 2.2 & 0.2 & 0.0 \\
\hline \multirow[t]{8}{*}{ participa-tion } & d2: General tasks and demands & 35.0 & 35.3 & 21.1 & 7.5 & 0.3 & 0.8 \\
\hline & d3: Communication & 74.0 & 18.1 & 4.3 & 3.2 & 0.0 & 0.4 \\
\hline & d4: Mobility & 11.4 & 27.2 & 27.4 & 20.1 & 10.8 & 3.1 \\
\hline & d5: Self-care & 26.9 & 37.2 & 19.6 & 10.7 & 4.8 & 0.7 \\
\hline & d6: Domestic life & 10.7 & 27.0 & 21.1 & 16.7 & 12.2 & 12.2 \\
\hline & d7: Interpersonal interactions and relationships & 51.4 & 35.8 & 6.9 & 2.8 & 0.6 & 2.5 \\
\hline & d8: Major life areas & 17.8 & 17.3 & 14.7 & 17.3 & 12.4 & 20.4 \\
\hline & d9: Community, social and civic life & 13.3 & 21.7 & 23.9 & 16.7 & 10.6 & 13.9 \\
\hline
\end{tabular}

*Qualifier scales of 0, 1, 2, 3, 4 stand for no, mild, moderate, severe and complete impairment, or limitation/restriction respectively.

diovascular, hematological, immunological and respiratory systems functions and genitourinary and reproductive functions were found to be least responded chapters, about $4 \%$ of participants had reported missing categories. In the domain of body structure, one third of participants (33.3\%) were not identified in the category related to structures of the cardiovascular, immunological and respiratory systems. In the chapter on learning and applying knowledge in the activity and participation domain, all participants $(100 \%$, $\mathrm{n}=90$ ) were documented as having some level of limitation/restriction including no problem and/or normal, whereas more than $20 \%$ of participants were identified as those whose functions of major life area were unknown. In the domain of environmental factors, no single chapters were documented for $100 \%$ of participants, and more than $70 \%$ of participants were identified as those whose categories in the chapter of support and relationships were positively affected.

Over $90 \%(\mathrm{n}=81)$ of participants were identified in five ICF categories about the neuromusculoskeletal and movement related functions (b715, b760, b735, b770, b730) as having a problem, while five categories (b110, b215, b510, b525, and b620) were coded as '0' which is qualified as no problem' or 'normal' for more than $75 \%$ of partici- pants $(n=68)$.

In the domain of body structure, a category related to structure of brain (s110) was reported as having some level of problems by $86.7 \%$ $(n=78)$ of participants. In activity and participation domain, more than $90 \%$ of participants were documented in eight categories related to domestic life (d630, d640), while major life areas (d855) and mobility (440, d450, d455, and d465) were documented as having some level of limitations or restriction. Fifteen ICF categories were reported as having a problem by over $10 \%(n=10)$ but less than $50 \%$ of the participants. Those are functions related to learning and applying knowledge (d166, d160, d170, d172, and d175), general tasks and demands (d210), communication (d325, d335, d350, d315, d330, d310, d360, d345), and interpersonal interaction and relationships (d760, d770, d710).

In the Environmental factor, nine categories were documented as a barrier by more than $10 \%(n=10)$ and less than $50 \%(n=45)$ of patients. These categories involved products and technology (el15, e120, e150 and e155), physical geography (e210), services, and systems and policies (e525, e540, e575, and e590). All categories were reported as a facilitator in more than 36\% of participants. However, no single category was documented as a facilitator in more than 
Table 2. Frequency of barrier/ facilitator in environmental factors. Each chapter refers to environmental factor components

(Unit: \%)

\begin{tabular}{|c|c|c|c|c|c|c|c|c|c|c|}
\hline \multirow{2}{*}{ Chapter } & \multicolumn{10}{|c|}{ Qualifier* } \\
\hline & 4 & 3 & 2 & 1 & 0 & +1 & +2 & +3 & +4 & Missing \\
\hline e1: Products and technology & 0.7 & 1.0 & 3.6 & 5.6 & 22.8 & 20.3 & 18.3 & 7.6 & 11.8 & 8.3 \\
\hline e2: Natural environment and human-made changes to environment & 2.2 & 0.0 & 4.4 & 5.6 & 40.0 & 13.3 & 12.2 & 2.2 & 8.9 & 11.1 \\
\hline e3: Support and relationships & 1.0 & 1.0 & 0.6 & 2.1 & 19.2 & 15.9 & 22.9 & 14.4 & 17.6 & 5.4 \\
\hline e4: Attitudes & 0.2 & 0.5 & 1.7 & 3.5 & 22.2 & 18.1 & 19.7 & 17.3 & 12.1 & 4.8 \\
\hline e5: Services, systems and policies & 0.9 & 1.8 & 2.7 & 5.9 & 27.8 & 23.3 & 12.8 & 6.4 & 9.9 & 8.6 \\
\hline
\end{tabular}

*The qualifier scale from 1 to 4 refers as a barrier, whereas from +1 to +4 represents a facilitator to environmental factors. ' 0 ' regarded as no influence in a patient's life.

$90 \%$ of participants. Five categories related to support and relationships (e310, e320, and e355) and attitudes (e410 and e450) were identified as facilitators in more than $75 \%$ of the patients but less than $90 \%$ of participants (Table 2).

\section{DISCUSSION}

The purpose of this study was to investigate functioning information in the current medical records for ninety patients, who had suffered stroke longer than 3 months and undergone inpatient rehabilitation services, using the ICF comprehensive ICF core set for stroke. It was found that the current medical records of patients with stroke may have functioning information. They were closely related to body function and activity \& participation which are common focus of rehabilitation services.

The most common problems found in the study were neuromusculoskeletal and movement impairments, which are the most common problems in patients with stroke, and impact heavily on patients' daily living and quality of life..$^{13}$ Therefore, a purpose of rehabilitation services is improving patients' neuromusculoskeletal and movement functions. In this study, over $90 \%(n=81)$ of participants had problems of stability in joint, muscle power and tone, control of voluntary movement, and gait pattern. Similar results have been reported in previous studies. ${ }^{10,14,15}$ It was found that consciousness was identified as 'no problem' or 'normal' in more than $81.6 \%$ of participants. This was due to the inclusion criteria of the current study, in which participants should have minimum score of 24 in the mini mental states examination.

In the body structure domain, brain structure (s110) was documented as having a problem in $86.7 \%(\mathrm{n}=78)$ of participants, which is consistent with the previous study.14In the current study, the structure of cardiovascular system was rated as 'missing value' in
$33.3 \%(n=30)$ of participants since the available information was not sufficient enough to make a judgement. Furthermore, no single category of body structure in ICF core set was rated 100\%. Information regarding anatomical structure was not frequently documented for patients' functioning status, and was not highly applied as outcome measures of whether an individual's level of functioning was improved or decreased over time.

In the domain of activity and participation, 4 categories were documented as a limitation or restriction in more than $90 \%(n=81)$ of participants. These categories are 'fine hand use', 'walking', 'moving around' and 'moving around in different locations', which had been previously observed in post-stroke populations and frequently reported as being limited and restricted. ${ }^{8}$ It was found listening function (d115) was identified as having no problem in $91.1 \%$ $(n=82)$ of patients. Interpersonal relationships were not reported as being limited or restricted in more than $50 \%(n=45)$ of participants though informal social relationships (d750) were reported as having problems with $41 \%(n=37)$ of patients. It was found that $21 \%(n=19)$ of the patients did not drive before they had a stroke. Categories of work and employment (d845-d855) were not also found to be suitable to use because the retired elderly comprised the proportion of patients (more than 25\%, $\mathrm{n}=23$ ) in the current study.

In the environmental factors, five categories were regarded as primary facilitators in more than $75 \%(n=79)$ of patients in the study. The support and assistance of immediate family, friends and health professionals could impact on patients' functioning status. Whereas nine categories were regarded as barriers in more than $10 \%(n=9)$ of patients, barrier factors like products and technology, geography, relevant services, systems and policies should be paid attention by government, policy decision-makers as well as relevant bodies in order to change existing environmental barriers.

Standardisation of heath information should be an important 
role of assessment and management in the clinical settings. ICF is the international classification for functioning status and commonly referred as a standard tool. Functioning information in the current medical recordings of ninety patients with stroke was investigated using the ICF coreset for stroke. It was found that the current medical records of patients with stroke contain functioning information. The results of the study were consistent with the general characteristics following stroke which appear in the form of neurological dysfunctions, eg. mobility and limited ability to perform activities of daily living. Environmental factors should be included to in order to understand patients' life situation which may influence patients' functioning.

Further study may be needed to establish standardisation of functioning information for patient with stroke, information should be collected from various institutes and/or organs like university hospitals, rehabilitation hospitals, specialized clinics and community based rehabilitation centres.

\section{REFERENCES}

1. Rosenbaum P, Stewart D. The world health organization international classification of functioning, disability, and health: A model to guide clinical thinking, practice and research in the field of cerebral palsy. Seminars in Pediatric Neurology. 2004;11(1):5-10.

2. Cieza A, Brockow T, Ewert T et al. Linking health-status measurements to the international classification of functioning, disability and health. JRehabil Med. 2002;34(5):205-10.

3. WHO. International classification of functioning, disability and health. Geneva: World Health Organization; 2001.

4. Stucki G, Cieza A, Melvin J. The international classification of function- ing, disability and health (ICF): A unifying model for the conceptual description of the rehabilitation strategy. J Rehabil Med. 2007;39(4):27985.

5. Duncan PW. Stroke disability. Phys Ther. 1994;74(5):399-407.

6. Song BK. The effect of upper extremity training with a focus on functional reaching, on trunk control and adl performance in post-stroke hemiplegic patients. J Kor Phys Ther. 2011;23(3):71-7.

7. Yang SH, Lee WH, Lee KS. The effects of modifed constraint-induced movement therapy and bilateral arm training on the upper extremity performance of individuals with chronic hemiparetic stroke. J Kor Phys Ther. 2011;23(5):65-72.

8. Kim JH. Relationship between gait symmetry and functional balance, walking performance in subjects with stroke. J Kor Phys Ther. 2014; 26(1):1-8.

9. Park J, So H, WS S. Effects of gluteus medius strengthening training using prssure biofeedback unit for msucle function and balance in stroke patients. J Kor Phys Ther. 2015;27(4):221-7.

10. Jung K, Kim Y, In T. Effects of the support surface condition on muscle activity of trunk muscles during balance exercises in patients with stroke. J Kor Phys Ther. 2015;27(4):196-200.

11. Cieza A, Ewert T, Üstün TB et al. Development of ICF core sets for patients with chronic conditions. J RehabilMed, Supple. 2004(44):9-11.

12. Lemberg I, Kirchberger I, Stucki G et al. The ICF core set for stroke from the perspective of physicians: A worldwide validation study using the delphi technique. Eur J Phys\& Rehabil Med. 2010;46(3):377-88.

13. Lin KC, Wu CY, Liu JS et al. Constraint-induced therapy versus dosematched control intervention to improve motor ability, basic/extended daily functions, and quality of life in stroke. Neurorehabilitation \& Neural Repair. 2009;23(2):160-5.

14. Wang P, Li H, Guo Y et al. The feasibility and validity of the comprehensive icf core set for stroke in chinese clinical settings. Clin Rehabil. 2014;28(2):159-71.

15. Ewert T, Fuessl M, Cieza A et al. Identification of the most common patient problems in patients with chronic conditions using the ICF checklist. Journal of Rehabilitation Medicine. 2004;36(SUPPL. 44):22-9. 
Appendix. The ICF core set code list with corresponding code labels of the graph

\begin{tabular}{|c|c|c|c|c|c|c|}
\hline Domain & Graph label & ICF code & Title & Graph label & ICF code & Title \\
\hline Body & 1 & b110 & Consciousness functions & 22 & b310 & Voice functions \\
\hline \multirow[t]{20}{*}{ function } & 2 & b114 & Orientation functions & 23 & b320 & Articulation functions \\
\hline & 3 & b117 & Intellectual functions & 24 & b330 & Fluency and rhythm of speech functions \\
\hline & 4 & b126 & Temperament and personality functions & 25 & b410 & Heart functions \\
\hline & 5 & b130 & Energy and drive functions & 26 & b415 & Blood vessel functions \\
\hline & 6 & b134 & Sleep functions & 27 & b420 & Blood pressure functions \\
\hline & 7 & b140 & Attention functions & 28 & b455 & Exercise tolerance functions \\
\hline & 8 & b144 & Memory functions & 29 & b510 & Ingestion functions \\
\hline & 9 & b152 & Emotional functions & 30 & b525 & Defecation functions \\
\hline & 10 & b156 & Perceptual functions & 31 & b620 & Urination functions \\
\hline & 11 & b164 & Higher-level cognitive functions & 32 & b640 & Sexual functions \\
\hline & 12 & b167 & Mental functions of language & 33 & b710 & Mobility of joint functions \\
\hline & 13 & b172 & Calculation functions & 34 & b715 & Stability of joint functions \\
\hline & 14 & b176 & $\begin{array}{l}\text { Mental function of sequencing complex } \\
\text { movements }\end{array}$ & 35 & b730 & Muscle power functions \\
\hline & 15 & b180 & Experience of self and time functions & 36 & b735 & Muscle tone functions \\
\hline & 16 & b210 & Seeing functions & 37 & b740 & Muscle endurance functions \\
\hline & 17 & b215 & Functions of structures adjoining the eye & 38 & b750 & Motor reflex functions \\
\hline & 18 & b260 & Proprioceptive function & 39 & b755 & Involuntary movement reaction functions \\
\hline & 19 & b265 & Touch function & 40 & b760 & Control of voluntary movement functions \\
\hline & 20 & b270 & $\begin{array}{l}\text { Sensory functions related to temperature } \\
\text { and other stimuli }\end{array}$ & 41 & b770 & Gait pattern functions \\
\hline & 21 & b280 & Sensation of pain & & & \\
\hline Body & 1 & s110 & Structure of brain & 4 & s730 & Structure of upper extremity \\
\hline \multirow[t]{2}{*}{ structure } & 2 & s410 & Structure of cardiovascular system & 5 & s750 & Structure of lower extremity \\
\hline & 3 & $s 720$ & Structure of shoulder region & & & \\
\hline Activity \& & 1 & d115 & Listening & 27 & d455 & Moving around \\
\hline \multirow[t]{17}{*}{ Participa-tion } & 2 & d155 & Acquiring skills & 28 & $d 460$ & Moving around in different locations \\
\hline & 3 & d160 & Focusing attention & 29 & d465 & Moving around using equipment \\
\hline & 4 & d166 & Reading & 30 & $d 470$ & Using transportation \\
\hline & 5 & d170 & Writing & 31 & $d 475$ & Driving \\
\hline & 6 & d172 & Calculating & 32 & d510 & Washing oneself \\
\hline & 7 & d175 & Solving problems & 33 & d520 & Caring for body parts \\
\hline & 8 & $\mathrm{~d} 210$ & Undertaking a single task & 34 & d530 & Toileting \\
\hline & 9 & d220 & Undertaking multiple tasks & 35 & d540 & Dressing \\
\hline & 10 & $\mathrm{~d} 230$ & Carrying out daily routine & 36 & d550 & Eating \\
\hline & 11 & d240 & $\begin{array}{l}\text { Handling stress and other psychological } \\
\text { demands }\end{array}$ & 37 & d570 & Looking after one's health \\
\hline & 12 & d310 & $\begin{array}{l}\text { Communicating with - receiving - spoken } \\
\text { messages }\end{array}$ & 38 & $d 620$ & Acquisition of goods and services \\
\hline & 13 & d315 & $\begin{array}{l}\text { Communicating with - receiving - } \\
\text { nonverbal messages }\end{array}$ & 39 & d630 & Preparing meals \\
\hline & 14 & d325 & $\begin{array}{l}\text { Communicating with - receiving - written } \\
\text { messages }\end{array}$ & 40 & $d 640$ & Doing housework \\
\hline & 15 & d330 & Speaking & 41 & d710 & Basic interpersonal interactions \\
\hline & 16 & d335 & Producing nonverbal messages & 42 & $d 750$ & Informal social relationships \\
\hline & 17 & d345 & Writing messages & 43 & d760 & Family relationships \\
\hline & 18 & d350 & Conversation & 44 & $d 770$ & Intimate relationships \\
\hline
\end{tabular}


Appendix. Continued

\begin{tabular}{|c|c|c|c|c|c|c|}
\hline Domain & Graph label & ICF code & Title & Graph label & ICF code & Title \\
\hline & 19 & d360 & $\begin{array}{l}\text { Using communication devices and } \\
\text { techniques }\end{array}$ & 45 & d845 & Acquiring, keeping and terminating a job \\
\hline & 20 & $\mathrm{~d} 410$ & Changing basic body position & 46 & d850 & Remunerative employment \\
\hline & 21 & $\mathrm{~d} 415$ & Maintaining a body position & 47 & d855 & Non-remunerative employment \\
\hline & 22 & $\mathrm{~d} 420$ & Transferring oneself & 48 & $\mathrm{~d} 860$ & Basic economic transactions \\
\hline & 23 & $\mathrm{~d} 430$ & Lifting and carrying objects & 49 & $\mathrm{~d} 870$ & Economic self-sufficiency \\
\hline & 24 & $\mathrm{~d} 440$ & Fine hand use & 50 & d910 & Community life \\
\hline & 25 & d445 & Hand and arm use & 51 & d920 & Recreation and leisure \\
\hline & 26 & $\mathrm{~d} 450$ & Walking & & & \\
\hline \multirow[t]{17}{*}{$\begin{array}{l}\text { Environ- } \\
\text { mental factor }\end{array}$} & 1 & e110 & $\begin{array}{l}\text { Products or substances for personal } \\
\text { consumption }\end{array}$ & 18 & e420 & Individual attitudes of friends \\
\hline & 2 & e115 & $\begin{array}{l}\text { Products and technology for personal use } \\
\text { in daily living }\end{array}$ & 19 & e425 & $\begin{array}{l}\text { Individual attitudes of acquaintances, peers } \\
\text { colleagues, neighbours and community members }\end{array}$ \\
\hline & 3 & e120 & $\begin{array}{l}\text { Products and technology for personal indoor } \\
\text { and outdoor mobility and transportation }\end{array}$ & 20 & $\mathrm{e} 440$ & $\begin{array}{l}\text { Individual attitudes of personal care providers } \\
\text { and personal assistants }\end{array}$ \\
\hline & 4 & e125 & Products and technology for communication & 21 & e450 & Individual attitudes of health professionals \\
\hline & 5 & e135 & Products and technology for employment & 22 & e455 & Individual attitudes of health-related professionals \\
\hline & 6 & e150 & $\begin{array}{l}\text { Design, construction and building products } \\
\text { and technology of buildings for public use }\end{array}$ & 23 & e460 & Societal attitudes \\
\hline & 7 & e155 & $\begin{array}{l}\text { Design, construction and building products } \\
\text { and technology of buildings for private use }\end{array}$ & 24 & e515 & $\begin{array}{l}\text { Architecture and construction services, } \\
\text { systems and policies }\end{array}$ \\
\hline & 8 & e165 & Assets & 25 & e525 & Housing services, systems and policies \\
\hline & 9 & e210 & Physical geography & 26 & e535 & Communication services, systems and policies \\
\hline & 10 & e310 & Immediate family & 27 & e540 & Transportation services, systems and policies \\
\hline & 11 & e315 & Extended family & 28 & e550 & Legal services, systems and policies \\
\hline & 12 & e320 & Friends & 29 & e555 & $\begin{array}{l}\text { Associations and organizational services, } \\
\text { systems and policies }\end{array}$ \\
\hline & 13 & e325 & $\begin{array}{l}\text { Acquaintances, peers colleagues, neighbours } \\
\text { and community members }\end{array}$ & 30 & e570 & Social security services, systems and policies \\
\hline & 14 & e340 & $\begin{array}{l}\text { Personal care providers and personal } \\
\text { assistants }\end{array}$ & 31 & e575 & General social support services, systems and policies \\
\hline & 15 & e355 & Health professionals & 32 & e580 & Health services, systems and policies \\
\hline & 16 & e360 & Health-related professionals & 33 & e590 & Labour and employment services, systems and \\
\hline & 17 & e410 & $\begin{array}{l}\text { Individual attitudes of immediate } \\
\text { family members }\end{array}$ & & & policies \\
\hline
\end{tabular}

